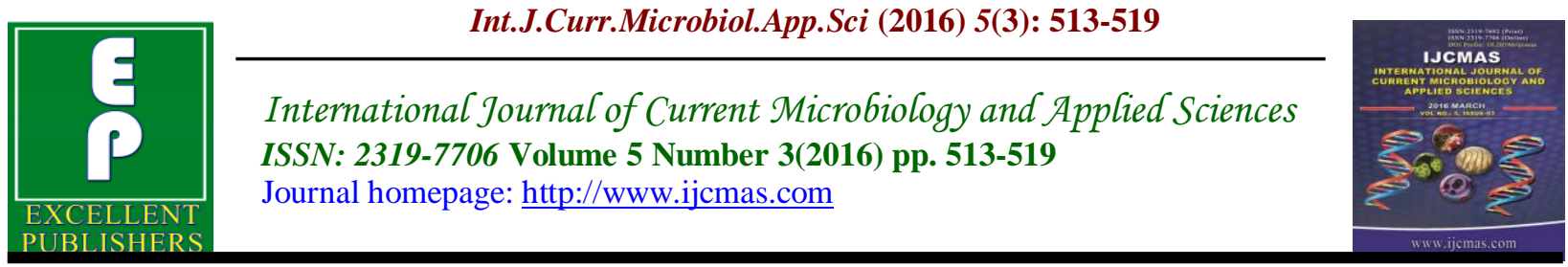

Original Research Article

http://dx.doi.org/10.20546/ijcmas.2016.503.060

\title{
A Study on Prevalence of Brucellosis in veterinarians and slaughter house workers in north Karnataka region, India
}

\author{
N. Pramod Sambrani*, B. Asha Patil and A.Divya \\ Department of Microbiology, Karnataka Institute of Medical Sciences, Hubli, Karnataka, India \\ *Corresponding author
}

\author{
A B S T R A C T
}

Keywords

Brucellosis,

Veterinarians,

Slaughter

House Workers

Article Info

Accepted:

20 February 2016

Available Online:

10, March 2016
Brucellosis is one of the most wide-spread zoonoses. Brucellosis is an occupational hazard of livestock farmers, dairy workers, veterinarians, slaughterhouse workers, and laboratory personnel, all of whom are considered to belong to the high-risk occupational group. So the above study was undertaken to know the prevalence of Brucellosis in veterinarians and slaughter house workers in North Karnataka region by using standard screening and confirmatory tests. A prospective laboratory based study. Blood samples of 100 veterinarians, 100 slaughter house workers and 100 adults who were not exposed to the risk of Brucellosis as controls were included in the study. Brucella antibodies were detected by serological tests. Rose Bengal Plate Test and Surface Fixation Test were used for screening. Standard Tube Agglutination Test was used as a confirmatory test. Statistical analysis done using chi square test. The prevalence of antibodies against Brucella among veterinarians and slaughter house workers was $14 \%$ and $26 \%$ respectively. Among 100 healthy controls none were seropositive. Standard Tube Agglutination Test was more sensitive than Rose Bengal Card Test and Surface Fixation Test ( $\mathrm{P}$ value <0.05). There was no significant difference between the two screening tests. There is high prevalence of Brucellosis among the slaughter house workers when compared to veterinarians. Awareness has to be created about the disease, its mode of transmission and preventive measures to be taken among slaughter house workers.

\section{Introduction}

Brucellosis is a zoonosis caused by the bacteria belonging to the genus Brucella. ${ }^{l}$ Currently there are six recognized species of Brucellaebased on phenotypic characteristics, antigenic variations and prevalence of infection in different animal hosts. Brucella abortusin cattles, Brucella melitensis in sheep and goats, Brucella suis in pigs, Brucella canis in dogs, Brucella ovis in sheep and Brucella neotomae in desert wood rats. Recently two Brucella strains from marine mammals have been reported as Brucella pinnipediae found in seals and Brucella cetaceae found in whales. ${ }^{2,3,4}$ Although B.melitensis accounts for most recorded cases, B.abortus and B.suis cause substantial morbidity. ${ }^{4,5}$ Brucellosis is an occupational hazard among veterinarians, slaughter house workers, dairy workers, 
shepherds, agricultural workers, animal husbandry personnel and it also constitutes an important public health problem in many developing countries. ${ }^{5}$ In spite of this, very few studies on brucellosis have been undertaken in the occupationally exposed groups. ${ }^{3,5}$ This study was conducted to assess the prevalence of antibodies to Brucella in veterinarians and slaughter house workers in North Karnataka Region.

\section{Materials and Methods}

The present study was conducted in the department of Microbiology, Karnataka Institute of Medical Sciences, Hubli. A total of 100 veterinarians, 100 slaughter house workers and 100 healthy adults with no history of exposure to the risk factors of Brucella infection, as control from Hubli and Dharwad areas were included in the study.

A detailed history of these individuals was collected with respect to their occupation, nature of work, history of consumption of raw milk, history of fever (nature and duration) in the past, complaints of joint pain etc. $5 \mathrm{ml}$ of blood sample was collected from each individual. The serum was separated and used for the following tests.

1. Rose Bengal Plate Test (RBPT). ${ }^{6}$

2. Rapid surface fixation test (Castaneda strip test, SFT). ${ }^{7,8}$

3. Standard tube agglutination test $(\text { STAT })^{9}$

All antigens for the test were procured from Indian Veterinary Research Institute (I.V.R.I), Izatnagar, UP. ${ }^{9}$

\section{Rose Bengal Plate Test}

One drop of antigen is added to one drop serum, mixed thoroughly by rotating the plate for 4 minutes and observed for the presence of agglutination. ${ }^{6}$

\section{Surface Fixation Test (Castaneda Strip Test)}

One drop of serum is taken over the filter paper strip at one end and to this one drop of coloured Brucella antigen is added. After two minutes the filter paper is dipped into the saline in a beaker.

If antibodies were present in the serum then the coloured Brucella antigen will be fixed. Hence no colour is raised up in the paper along with the saline, which is interpreted as a positive result.

If antibodies are absent coloured Brucella antigen will not be fixed. The saline will be seen raising in the strip carrying with it the coloured antigen and giving the appearance of a Comet's tail or tongue shape, which is interpreted as negative result. ${ }^{7,8}$

\section{Standard Tube Agglutination Test}

Serum was diluted by using phenol saline. Equal volume of doubling dilution of serum is mixed with standardized Brucella antigen suspension. Incubated at $37^{\circ} \mathrm{C}$ for 20 hours \pm 1hour. Five antigen control tubes, showing $0 \%, 25 \%, 50 \%, 75 \%, 100 \%$ agglutination were incubated along with the test samples. ${ }^{9}$

\section{Recording of Results}

Results of agglutination were noted after keeping the tubes for half an hour on the bench at the room temperature.

All the tubes were compared with opacity standard of the supernatant fluid in the III antigen control tube, which corresponds to 
$50 \%$ agglutination.

To express in International Units (IU) per $\mathrm{ml}$ of serum, the serum titre showing 50\% agglutination was doubled.

Titre of 80 IU per $\mathrm{ml}$ or above is considered positive for brucellosis in human being. ${ }^{10,11,12}$

Statistical analysis was done using chi square test.

\section{Results and Discussion}

Among one hundred Veterinarians, 14(14\%) were seropositive for Brucella antibodies. Out of 100 slaughter house workers, $26(26 \%)$ were seropositive. None of the serum samples of healthy adults were positive for antibodies against Brucella.

Most of the (30.76\%) seropositive veternarians were in the age group of 5160 years and slaughter house workers were in the 11-20 years age group (66.6\%).

The lowest prevalence of brucellosis was observed among veterinary doctors $6.66 \%$ and highest prevalence of brucellosis is among veterinary inspectors 19.04

Table 1 shows the prevalance of Brucellosis among the different cadres of the veterinarians.

Comparison of the antibody titre between Veterinarians and Slaughter house workers is shown in table 2 .

A titre of 80 I.U./ml. was observed among $6(42.85 \%)$ of veterinarians. One sample showed prozone phenomenon which had a titre of 2560 I.U./ml.
Among the slaughter house workers majority (53.84\%) had a titre of 160 I.U./ml.

$27(18 \%)$ cases were found to be positive by STAT, $20(13.33 \%)$ by RBPT and $15(10 \%)$ by SFT.

Comparison of results of positive sera at or above diagnostic titre by STAT, RBPT, and SFT is shown in table 3.

Human brucellosis presents with protean manifestations and its complications can affect almost all organs and system with varying incidence, which often lead to misdiagnosis. ${ }^{1}$

The routes of transmission are through direct contact, ingestion, inhalation and accidental inoculation. Milk and milk products, meat, aborted materials, vaginal discharges, urine, dried material of animal origin such as dust from wool of infected animals are potential sources of infection. ${ }^{1,2}$ Brucellae may be inhaled in aerosol form in slaughter houses, laboratories and in animal husbandary field workers, so this infection is notified as occupational hazard. ${ }^{1}$

The incubation period is estimated to be about 2-6 weeks but may be as long as several months. Brucellosis may present as acute disease, or as a chronic disease of insidious onset. ${ }^{3,4}$

Undulant fever is the classical pattern described by Bruce. The fever tends to occur in the evening and night with normal temperature maintained during the day over a period of 2-3 weeks. After this for several days patient will be afebrile and feels relatively well, only to experience another cycle of waxing and waning fever. This is due to containment of pathogens in 
tissue granulomas and subsequent release back into circulation. This form represents $25 \%$ to $30 \%$ of cases in endemic areas and usually reflects incomplete treatment, failure of standard treatment or lack of proper initial diagnosis and therapy. ${ }^{13,14,15}$
The chronic infection is a feature that has long been associated with brucellosis, causing prolonged fever and recrudescent infection for more than one year with symptom free periods in between.,

Table.1 Shows the Seroprevalance of Brucellosis in Different Cadres of Veterinarians by Standard Tube Agglutination Test

\begin{tabular}{|l|l|lr|l|}
\hline Cadres & $\begin{array}{l}\text { No. of sera } \\
\text { tested }\end{array}$ & $\begin{array}{l}\text { No.of } \\
\text { positive } \\
\text { IU/ml }\end{array}$ & $\begin{array}{r}\text { sera } \\
\mathbf{8 0}\end{array}$ & Percentage \\
\hline Veterinary Doctors & 15 & 1 & $6.66 \%$ \\
\hline Veterinary supervisors & 16 & 2 & $12.5 \%$ \\
\hline $\begin{array}{l}\text { Senior veterinary } \\
\text { inspectors }\end{array}$ & 23 & 3 & $13.04 \%$ \\
\hline Veterinary inspector & 21 & 4 & $19.04 \%$ \\
\hline Veterinary assistants & 25 & 4 & $16 \%$ \\
\hline Total & 100 & 14 & $14 \%$ \\
\hline
\end{tabular}

Table.2 Shows the Comparison of Antibody Titre by Standard Tube Agglutination Test. (Diagnostic Titre>80 IU/ml) between Veterinarians and Slaughter House Workers

\begin{tabular}{|l|l|l|}
\hline Antibody titre(IU /ml) & $\begin{array}{l}\text { Seropositive cases in } \\
\text { veterinarians }\end{array}$ & $\begin{array}{l}\text { Seropositve cases in } \\
\text { slaughter houseworkers }\end{array}$ \\
\hline 80 & 6 & 4 \\
\hline 160 & 3 & 14 \\
\hline 320 & 4 & 8 \\
\hline 640 & 0 & 0 \\
\hline 1280 & 0 & 0 \\
\hline 2560 & 1 & 0 \\
\hline Total & 14 & 26 \\
\hline
\end{tabular}

Table.3 Shows the Comparison of Results of Positive Sera at or above Diagnostic Titre (> 80 IU/ml) by Standard Tube Agglutination Test, Rose Bengal Plate Test, SurfaceFixation Test

\begin{tabular}{|l|c|c|c|}
\hline Study group & $\begin{array}{l}\text { No. of positive } \\
\text { sera by STAT }\end{array}$ & $\begin{array}{l}\text { No. of positive } \\
\text { sera by RBPT }\end{array}$ & $\begin{array}{l}\text { No. of positive } \\
\text { sera by SFT }\end{array}$ \\
\hline Veterinarians(n=100) & 14 & 9 & 7 \\
\hline $\begin{array}{l}\text { Slaughter house workers } \\
(\mathrm{n}=100)\end{array}$ & 26 & 22 & 16 \\
\hline $\begin{array}{l}\text { Healthy individuals } \\
(\mathrm{n}=100)\end{array}$ & 0 & 0 & 0 \\
\hline Total $(\mathrm{n}=300)$ & 40 & 31 & 23 \\
\hline
\end{tabular}


Two patterns of chronic Brucellosis can be seen. The first is a cyclic course with back pain, arthralgias, sweating and depressive mood. This pattern is very similar to the chronic fatigue syndrome and occurs more frequently in women, especially women older than 40 years of age. The second chronic form is localized spondylitis or uveitis (or episcleritis) without fever or systemic symptoms. This form is frequent in adults and affects both sexes equally. ${ }^{16}$

If neglected it may lead to complications of various organs like arthritis of knee, sacroiliac and sternoclavicular joints. ${ }^{16} \mathrm{It}$ may involve the Hepatobiliary system causing chronic suppurative abscess of the liver and spleen, pancreatitis, spontaneous peritonitis and cholecystitis. ${ }^{1}$

Acute or chronic meningitis is the most frequent nervous system complication and clinically it can resemble multiple sclerosis. The prognosis of treated neurobrucellosis is generally favourable. ${ }^{17}$

Endocarditis occurs in fewer than $2 \%$ of cases, but accounts for the majority brucellosis related deaths. ${ }^{1}$

Brucellosis during pregnancy is associated with poor fetal prognosis with a high rate of abortion, miscarriage, prematurity and fetal death. ${ }^{1}$

Hematologic manifestations of brucellosis include anemia, leucopenia, thrombocytopenia and clotting disorders. Granulomas are found in the bone marrow in up to $75 \%$ of cases. Rarely, severe thrombocytopenia with cutaneous purpura and bleeding from mucosal sites can occur. $^{18}$

The present study revealed that the prevalence of brucellosis in veterinarians was $14 \%$. Which is in concurrence with that of Mudaliar et all and Agastya et all. $^{13,14}$ The prevalence of brucellosis in slaughter house workers was $26 \%$. Other studies have reported prevalence ranging from 17.3 to $67.3 \%$ in veterinarians and 20 to $52.4 \%$ among slaughter house workers. ${ }^{3,12,15}$

The prevalence of brucellosis among veterinarians is highest $(30.76 \%)$ in the 51-60 years age group and lowest $(5.55 \%)$ in the 21-30 year age group. This shows probably increased risk due to prolonged occupational exposure.

Among slaughter house workers majority $(66.6 \%)$ of seropositive individuals were in the 11-20 year age group and lowest $(20 \%)$ in 31-40 year age group. Very young people were seen working in slaughter house which may be due to poor socio economic condition.

A titre of $160 \mathrm{I} . \mathrm{U} / \mathrm{ml}$. observed in $37 \%$ of individuals. Only one sample showed prozone phenomena with a titre of 2560 $\mathrm{IU} / \mathrm{ml}$. Five samples showed titre below $80 \mathrm{IU} / \mathrm{ml}$,which were interpreted as negative.

The lowest prevalence was among the veterinary doctors, which may be explained due to the awareness of the disease and taking protective measures like using gloves and wearing mask.

The higher prevalence in veterinary inspectors and veterinary assistants can be explained due to the negligence or ignorance regarding protective measures.

The difference in the values of STAT when compared with RBPT and SFT was statistically significant $(\mathrm{P}<0.001)$ and it was observed that STAT had a sensitivity of $74.1 \%$, specificity of $100 \%$, positive predictive value of $100 \%$ and negative predictive value of $94.6 \%$. 
There was no statistically significant difference between SFT and RBPT.

The seropositive cases gave vauge history of fever, myalgia and arthralgia and most of them were diagnosed as suffering from flu or viral fever.

All positive cases were treated with Rifampicin 450mg o.d.and Co-trimoxazole DS b.i.d. orally for six weeks. ${ }^{1}$

The prevention of human Brucellosis depends on the elimination of the disease in domestic live- stock. In many countries, the use of Brucella abortus strain 19 vaccine in cattle and Brucella melitensis strain Rev 1 vaccine in goats and sheep has resulted in the near elimination of brucellosis in these animals. Brucellosis surveillance and eradication programmes are very expensive. In many developing nations, such a commitment remains elusive. $^{1,5}$.

Preventive measures such as use of gloves, masks and goggles provide effective barriers against exposure to blood and secretions of potentially infected animals. Boiling or pasteurizing milk effectively kills Brucellae in dairy products making it safe for human consumption. ${ }^{1,5}$

Multiple organ system involvement by Brucella in the chronic stage makes it still more necessary to detect its presence in the early stage. Early diagnosis and proper treatment along with health education in preventive measures constitute important and economical tools to reduce the prevalence of Brucellosis in developing countries like India.

In conclusion, there is high prevalence of Brucellosis among the slaughter house workers when compared to veterinarians.
Awareness has to be created about the disease, its mode of transmission and preventive measures to be taken among slaughter house workers and negligiance and ignorance regarding protective measures among veterinarians has to be removed.

\section{Acknowledgement}

I sincerely acknowledge with gratitude to late Dr. Basavaraj Guragol. Professor, Department of Microbiology, KIMS, Hubli and Dr. Ron, who helped immensely in completion of this study.

\section{References}

1. Corbel MJ, BeechingNJ. Brucellosis. In: Braunwald EB, Hauser SL, Faucci As, Longo DL, Kasper DL, Jameson JL, eds. Harrison's principles of internal medicine, New York, McGraw Hill Vol.1,15 ${ }^{\text {th }}$ ed;2001:986-989.

2. Mantur BG, Biradar MS, Bidri RC, Mulimani MS, Veerappa K, Kariholu P. Protein clinical manifestations and diagnostic challenges of human brucellosis in adults.16 years experience in endemic area. J Med Microbiology 2006;55:897-903.

3. Rana UVS, Sehgal S, Bhardwaj M. A sero epidemiological study of brucellosis. Among workers of veterinary hospitals and slaughter house workers of union territory of Delhi. Int J Zoonoses 1985;12:74-79.

4. 19Spink WW, Thompson H. Human Brucellosis caused by Brucella abortus, strain, JAMA 1953;153:116265.

5. Marshall DF, Arnold F K. Brucellosis in US 1965-1974. Journal of Infectious disease 1977;136(2).

6. Protocol of Rose Bengal Plate Test. IVRI, Izatnagar, UP. 
7. Castaneda MR. Laboratory diagnosis of Brucellosis in man. Bull WHO 1961;24:73-84.

8. Joint $\mathrm{FAO} / \mathrm{WHO}$ Expert Committee on Brucellosis. Fifth Report (Geneva 70) Technical Report Series No. 464 1971:1.

9. Protocol of Brucella serum agglutination test IVRI, Izatnagar, UP.

10. Alton C.G, Jones LM and Pietz DEC. Laboratory techniques in Brucellosis, monograph series $\quad 2^{\text {nd }} E d n \quad$ WHO Geneva 1975.

11. Spink WW. The laboratory in the diagnosis of Brucellosis. Am Jour Clin Path 1952;22:201-210.

12. RJ Henderson, HILL MD, Vickers AA, Edwards JM, Tillett $\mathrm{H}$. Brucellosis and veterinary surgeons British Medical Journal 1975;2:656659.

13. Mudilar S, Bhore A, Pandit. Detection of antibodies to brucellaabortus in animal handlers. India $\mathbf{J}$ Med Sci 2003;57:181-186.

14. Agasthya AS, Isloor S, Prabhudas K. Brucellosis in high risk group individuals. Indian J Med. Microbiology 2007;25:28-31.

15. A Karmi, A Alborzi, M Rasooli, MR Kadivar, AR Natehian. Prevalnece of antibody to brucella species in butchers, slaughter house workers and others. Eastern Mediterranean Health Journal January 2003;9(1/2).

16. Robert M Lifeso, Edward Harder, Scott J McCorkell. Spinal brucellosis. The journal of Bone and Joint Surgery 1985;67B:345-49.

17. Akdeniz $\mathrm{H}$, Iramark $\mathrm{H}$, Anlar $\mathrm{O}$, Demiroz AP. Central nervous system brucellosis - Presentation, diagnosis and treatment. J Infect 1998;36(5):297-301.

18. Crosby E, Llosa L, Miroquesada M Haematologic changes in Brucellosis. J Infect Dis 1984; 150:419-424.

19. Lyall M. Ocular Brucellosis. Trans OpthalmolSocUK 1973;93:689-694.

\section{How to cite this article:}

Pramod Sambrani, N., B. Asha Patil and Divya, A. 2016. A Study on Prevalence of Brucellosis in veterinarians and slaughter house workers in north Karnataka region, India. Int.J.Curr.Microbiol.App.Sci. 5(3): 513-519. doi: http://dx.doi.org/10.20546/ijcmas.2016.503.060 